\title{
The Electronic Spatial Information System - tools for the monitoring of asbestos in Poland
}

\section{Abstract}

On January 1, 2005 the use of asbestos-containing products was banned in the European Union. According to the Act of 19 June 1997 banning the use of these products, their usage in Poland should be abated by the end of 2032. The whole process is being monitored by the Electronic Spatial Information System for the Monitoring of Asbestos Products Removal. The system design was based on a geodatabase. The research area of the study is the whole territory of Poland at the national, provincial and local level of detail. The monitoring process embraces spatial analysis through the preparation and interpretation of a range of maps. The results obtained from the deployed methods proved that the system has been useful for decision making purposes during the monitoring process. The proposed solutions were appreciated by the EU.

Keywords

Asbestos $\cdot$ asbestos-containing products $\bullet$ GIS $\cdot$ monitoring $\cdot$ asbestos removal process $\cdot$ Poland

(c) University of Warsaw - Faculty of Geography and Regional Studies

\author{
Małgorzata Krówczyńska ${ }^{1}$ \\ Ewa Wilk ${ }^{2}$ \\ Bogdan Zagajewski ${ }^{3}$ \\ 'Department of Geoinformatics and Remote Sensing \\ Faculty of Geography and Regional Studies \\ University of Warsaw; \\ WGS84 Polska Sp. z o.o., Milanówek, Poland \\ e-mail:mkrowczynska@uw.edu.p \\ 2Department of Geoinformatics and Remote Sensing \\ Faculty of Geography and Regional Studies \\ University of Warsaw; \\ WGS84 Polska Sp. z 0.0., Milanówek, Poland \\ e-mail: ewa.wilk@student.uw.edu.pl \\ ${ }^{3}$ Department of Geoinformatics and Remote Sensing \\ Faculty of Geography and Regional Studies \\ University of Warsaw \\ e-mail:bogdan@uw.edu.pl \\ Received: 27 December 2013 \\ Accepted: 5 May 2014
}

Introduction and motivation

The term asbestos means chrysotile, amosite, crocidolite, tremolite, anthophyllite and actinolite (Ross et al. 2007). Its unique set of physical and chemical properties (Virta 2002), such as incombustibility, low electrical conductivity, thermal stability, resistance to biodegradation and chemical inertia toward most chemicals, has led to many industrial applications of asbestos (Virta 2003). Asbestos and asbestos fibres have been used in many products for a range of applications, such as roofing coatings (flat and corrugated sheets), pipes, floors, textiles, rope, cord and yarn, paper, friction and composition materials, household products, plastic fillers (Dunnigan 1993), as well as clutches and brake linings, gaskets and pads for automobiles (Thompson \& Mason 2002).

Exposure to asbestos and asbestos dust causes a wide range of diseases, such as lung cancer, mesothelioma and asbestosis. In order to eliminate asbestos-related diseases, the World Health Organization and the International Labour Organization have recommended ceasing the usage of all types of asbestos (WHO 2006).

The European Union aimed to lay down measures and to supplement provisions in the interests of the protection of human health and the environment, in order to prevent and reduce pollution by asbestos as stated in Council Directive 87/217/EEC of 19 March 1987 on the prevention and reduction of environmental pollution by asbestos. On January 1, 2005 (following directive 76/769/CEE) the use of asbestos-containing products was banned in the European Union.

According to the Act of 19 June 1997 banning the use of asbestos-containing products and the amending Ordinance of the Minister of Economy of 13 December 2010, the usage of asbestos containing products in Poland should be abated by the end of 2032. The abatement process is being led under the auspices of the Ministry of Economy with the implementation of the Programme for Asbestos Abatement in Poland 2009-2032 (Resolution No. 39/2010 of the Council of Ministers). Since Geographical Information Systems are widely used in business development and government issues (Overman 2010), the asbestos removal monitoring process in Poland is being carried out with the usage of the Electronic Spatial Information System for the Monitoring of Asbestos Products Removal.

In this context, it should be recalled that spatial data analysis may be undertaken where the geographical referencing of objects contains important information (Goodchild \& Haining 2004). Geographic data may vary from the points of observations of single geo-referenced attributes to large databases of complex information (Goodchild et al. 2007). Environmental assessment and GIS-based models are used to assess and describe the impact or performance of different phenomena on the surrounding environment (Abbaspour \& Soltaninejad 2004; Abbaspour et al. 2005; Salman Mahini \& Gholamalifard 2006; Zerrouqi et al. 2008). A large amount of information may constitute the basis for GIS analysis and therefore be entered into the system (Longley, Goodchild \& Rhind 2005). The role of the geographical information system is to integrate and analyse available data for evaluation and monitoring purposes (Salem 2003). Data on environmental issues collected and stored in databases is adequate for management and analysis undertaken using GIS (Aspinall 1995). The use of GIS tools always brings advantages in the management of processes where the thorough analysis of geographic information is required. GIS solutions 
enable the collection of a structured data set in reference to aerial or satellite imagery (O'Sullivan \& Unwin 2010). Geospatial analysis makes use of geographic information that connects features and phenomena on the Earth's surface to their locations (de Smith, Goodchild \& Longley 2011). The spatial data in a GIS are envisaged as geographically referenced which can be shown by their location storage either in latitude/longitude coordinates or in a projected coordinate system (Ungerer \& Goodchild 2002). The crucial benefit of using GIS for the Managing Board of the Program for Asbestos Abatement in Poland is the supportive role in the decision-making process on the basis of precise and up-to-date digital maps. The maps are fully capable of revealing hidden spatial phenomena (Skryzhevska, Green \& Abbitt 2013). Asbestos data collection in the Electronic Spatial Information System for the Monitoring of Asbestos Products Removal is carried out with reference to the land and property register.

Therefore, it is clear that GIS tools and analytical methods are of great interest and potential to support the monitoring of asbestos usage and the abatement process in Poland, and the purpose of the study is to present how the features of Geographic Information Systems are presently used in this context.

Since the data on asbestos-containing products are gathered in a descriptive form in the asbestos-containing products database, in order to develop a GIS system there was a need to transpose the collected data and assign them geographical references. The land register was the reference database. GIS tools are visual, and have the potential to display information visually, allowing large portions of information to be analysed very quickly (Goodchild 2000). They are used to analyse and manage spatially distributed data connected to a geographical region, which is appreciated as a tool for the decision-making process in other industries besides government agencies (Rob 2003).

\section{Research methods}

The Electronic Spatial Information System for the Monitoring of Asbestos Products Removal is a computerized system for the input, storage, management, display and analysis of data that can be linked to a geographic location (Rob 2003). System development was based on a relational geodatabase which integrated data from various sources. Geodatabases should have the proper data structure and indices in order to realize queries and transactions effectively (Bouziania, Goïtab \& Heb 2010). Reference databases and glossaries were implemented in the system development process. It was decided that the land and property register be built into the system as land parcel identification numbers are known reference points for locating asbestos-containing products in space. Land parcels are measured and can be described and expressed in GIS since they have a hierarchical framework and form closed polygons (Putra, Wenjing \& Yang 2003).

The key task was to define the set of source data to be used in the system development and the relationships between them. The database structure was then validated against user requirements for filling, updating and accessing data. Rules of no duplication, simplicity and clarity of data were applied.

The land register and asbestos-containing products data gathered were implemented in the system. The asbestos data were derived from the database of asbestos-containing products which is the tool used by the Ministry of Economy to gather and process information from the inventory carried out by local governments. Among others, the following are of key interest for the system development:

1. Administrative localization (province, district, local government, city/town/village, street, number of property),

2. Geodetic data (number of geodetic region, parcel identification number consisting of the unique attributes of 12 digits: province, district, local, geodetic region, land parcel identification number),
3. Asbestos-products data (quantity of products used, type of products used, state of products used, i.e. when they should be abated according to legal regulations, type of buildings, quantity of products abated).

One of the system design requirements was the transposition of descriptive data from the asbestos-containing products database to the PostgreSQL database. The PostreSQL database is fully compatible with the asbestos-containing products database. Having prepared SQL queries for each of the analysed phenomena, the maps and analysis are prepared automatically even if changes to the asbestos-containing products were experienced during the period. The land parcel identification number took the role of the unique identification number through which all other data were interconnected.

There are about 747,000 records stored in the asbestoscontaining database which have been assigned the attribute of a land parcel identification number (Figure 1). All the records which had been denoted in the asbestos-containing products database and had the proper attributes assigned (geodetic region number and land parcel identification number) were compared to the land property register. As a result of this operation it was derived on which land parcels there are asbestos-containing products used, which need to be abated. On the basis of the land parcels' centroid coordinates an asbestos layer was generated which was the input for further analysis to be undertaken.

The primary source of spatial information was the National Register of Boundaries (Ordinance of the Council Ministers of 10 January 2012 on the national register of boundaries) as the official database containing details of the administrative division of Poland and areas of provinces, districts and local governments. Also the following layers, derived from the General Geographic Database of Poland (Ordinance of the Minister of Interior and Administration of 17 November 2011), were used in the system development: land use and land cover, protected areas, transport and geographical names. Orthophotomaps constitute an independent input for the local level - the lowest level of system design. This allows for the presentation and verification of inventory results at the local level. The leading source of data for the local level is the land and property register. It allows for the localization of each object in reference to the land register. Each asbestos-containing object was then referred to a geographical location.

\section{Investigated area}

The research area of the study consisted of the whole territory of Poland.

The system construction was divided into three parts, each forming a separate level of analysis.

The highest level of analysis is the national level, made up of 16 provinces (voivodeships). It is used by the Polish administration to undertake the process of management of the Programme for Asbestos Abatement in Poland 2009-2032 (Resolution No. $39 / 2010$ of the Council of Ministers). The national level was developed in order to present aggregated information about general trends and progress made in the asbestos abatement process. It is mainly used for general reporting purposes.

The second level of analysis is the provincial level, with reference to 379 districts. GIS analyses are dedicated for the provincial administration to plan activities to be undertaken and to report results on the national level.

The lowest level of analysis is the local government, which is the basis for the operational activity of the system. It collects data on asbestos usage and abatement from 2,478 local governments and provides the most accurate information in reference to the unique record where the asbestos products are used. 


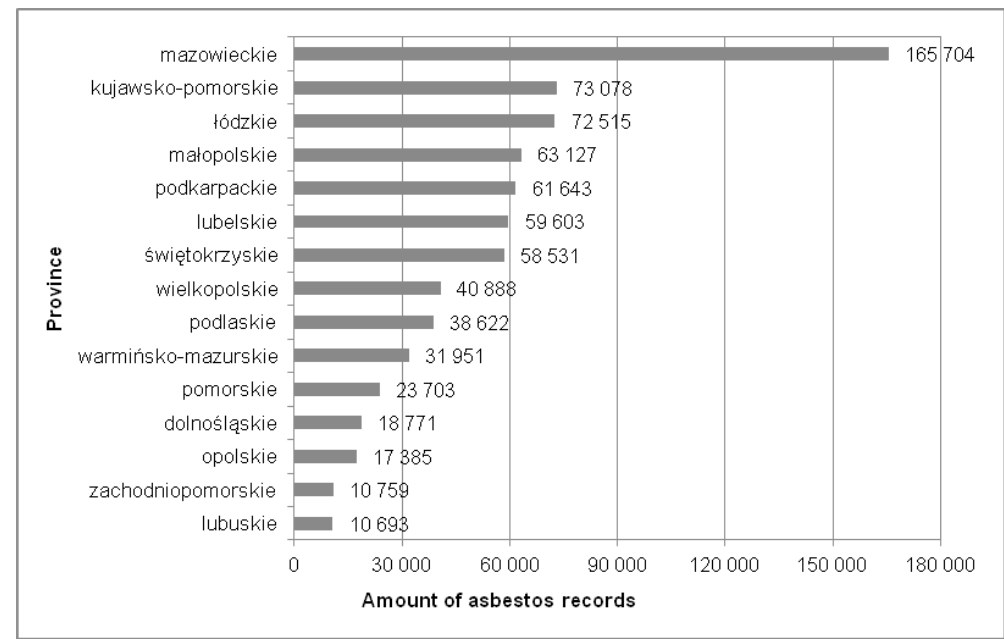

Figure 1. Amount of records with the identification land parcel number filled

\section{LEGEND}

Amount of asbestos-containing products [tons $/ \mathrm{km}^{2}$ ]

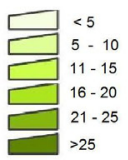

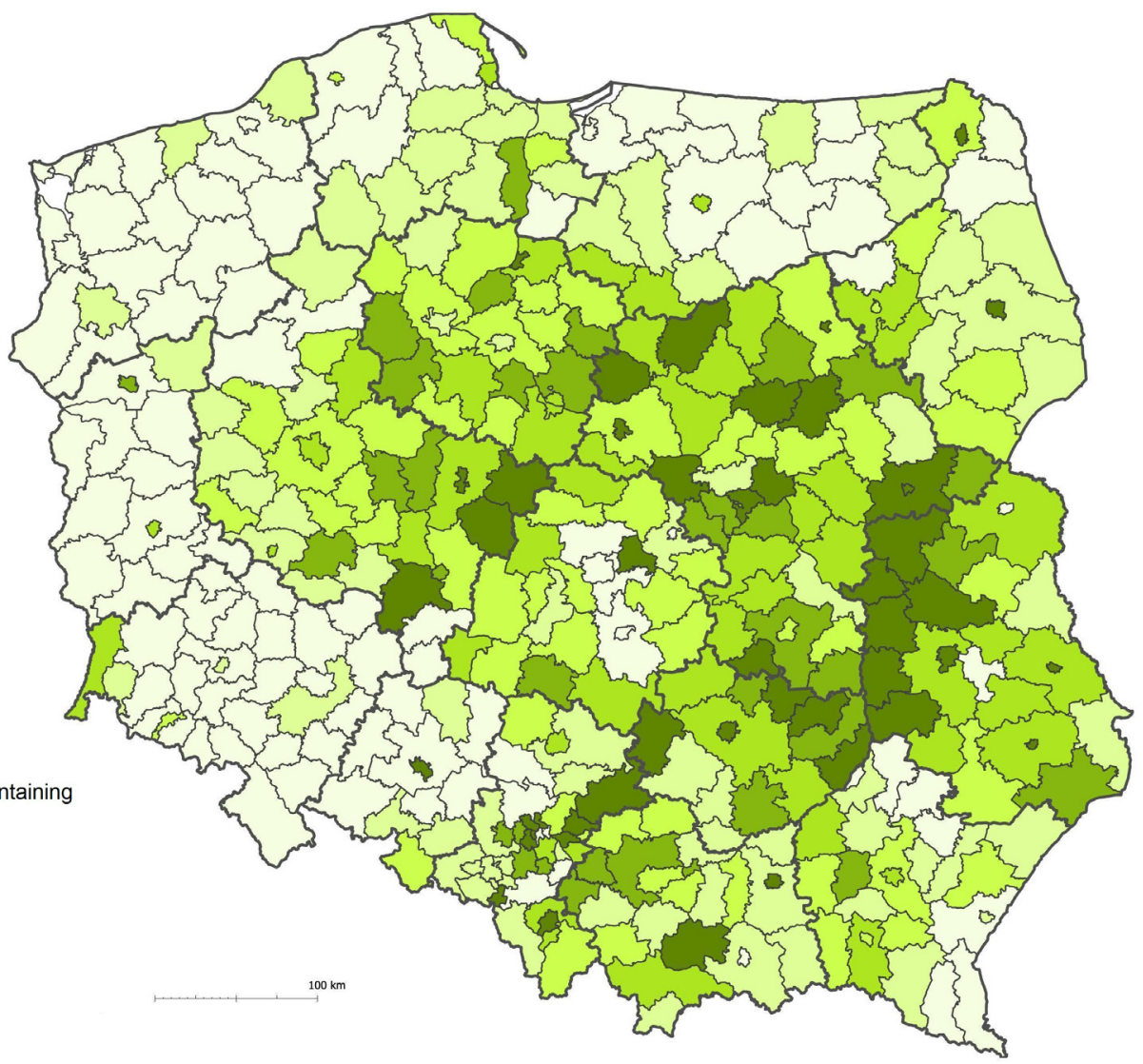

Figure 2. Asbestos-containing product distribution in Poland. National level

The monitoring process of asbestos-containing products usage and abatement is carried out through the spatial analysis conducted at the predefined three levels of management, based on data aggregation with the use of:

1. maps of asbestos distribution, presenting the asbestos distribution throughout the country in given intervals of quantities of asbestos used (Figure 2), connected to the area of the administrative units of Poland,

2. maps of the urgency of asbestos removal, presenting how the process of asbestos removal will progress up until 2032 (the date of final asbestos abatement, Figure 3),
3. maps of quantities of asbestos abated, showing how the asbestos abatement process is proceeding (Figure 4).

A set of maps and analysis is prepared and interpreted for each reporting period, since the monitoring process is an ongoing activity. At the local level, an additional analysis referring to the verification of the quantity of asbestos-containing products is used.

At the present stage of the system development, the system is fully operational at the national and provincial level. The local level is still being improved because of the ongoing modernization 


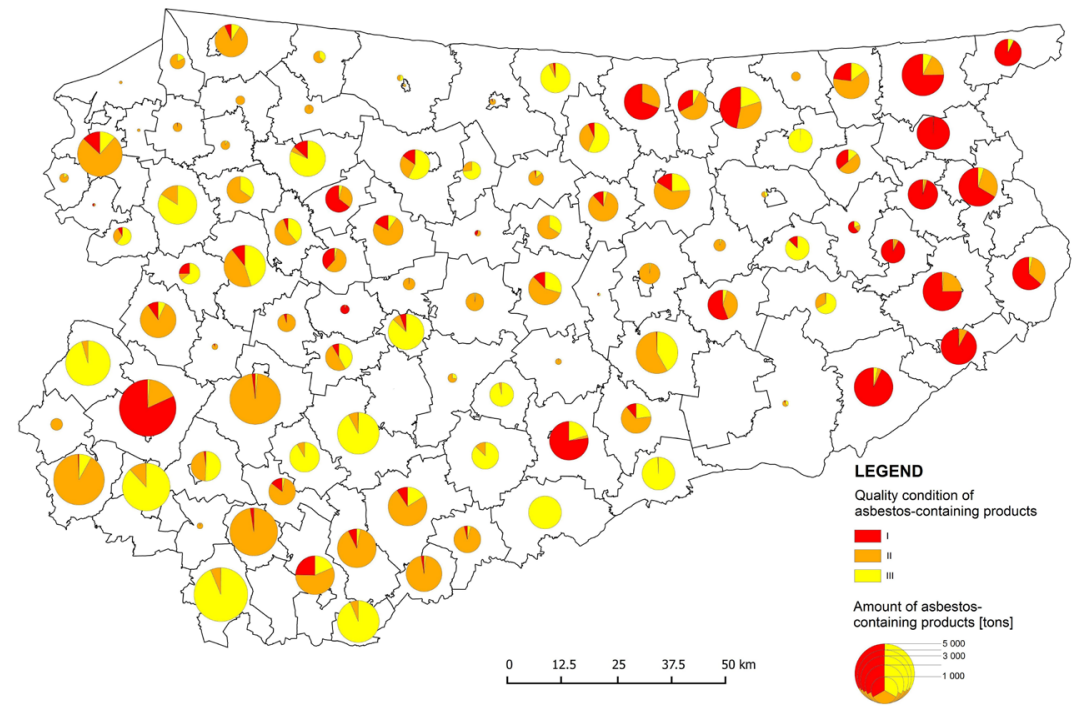

Figure 3. Level of urgency of asbestos removal. Provincial level

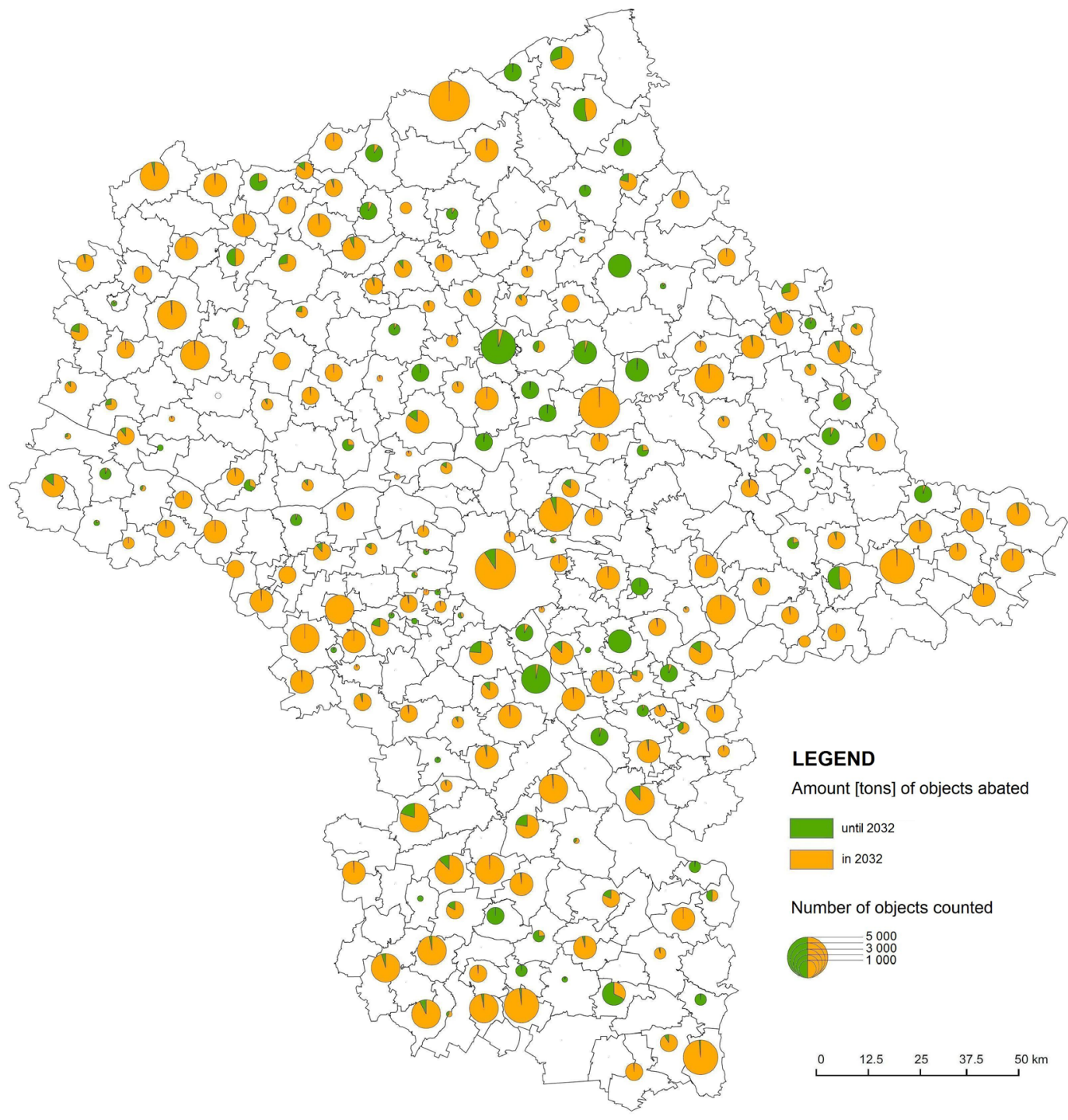

Figure 4. Quantities of asbestos abated and plans for removal. Provincial level 
of the land and parcel register being undertaken by the Polish government authorities.

\section{Results}

The Electronic Spatial Information System for the Monitoring of Asbestos Products Removal based on Geographic Information Systems is not only used for the presentation of inventory taking of asbestos-containing products. It is the main tool for the monitoring of the implementation process of the Program for Asbestos Abatement in Poland. In order to present an analysis of asbestos layer results, data were aggregated to the national and provincial levels. The outcomes of the analysis are presented as: asbestos-containing product distribution throughout Poland (in tons per $\mathrm{km}^{2}$, excluding forestry areas since no asbestoscontaining products should be found there), asbestos urgency removal rate, quantities of asbestos abated (showing how the asbestos abatement process is proceeding), the owners and users of asbestos-containing products (legal and private) to address informative and corrective actions, and the amount of records stored in the asbestos-containing products database (as at the date of measurement and over the whole reporting period, in order to draw conclusions about the inventory-taking process). All of these analyses are just examples of possible data preparation showing how the asbestos abatement process is proceeding and they constitute the basis for interpreting the results which are the main indicators of progress in the realization of the program at the national, provincial and local levels.

The activities undertaken by Poland, the results obtained and the implementation of the monitoring requirements were appreciated by the EU Parliament. In 2013, according to the European Parliament resolution of 14 March 2013 on asbestosrelated occupational health threats and prospects for abolishing all existing asbestos (2012/2065(INI), Poland was appointed the only country in the EU to have adopted the action plan for an asbestos-free country and to be monitoring its realization.

\section{References}

Abbaspour, M \& Soltaninejad, A 2004, 'Design of an environmental assessment model on the effect of vehicle emission in greater Tehran on air pollution with economic sensitivity', Int. J. Environ. Sci. Tech., vol. 1, no. 1, pp. 27-38.

Abbaspour, M, Javid, AH, Moghimi, P \& Kayhan, K 2005, 'Modeling of thermal pollution in coastal area and its economical and environmental assessment', Int. J. Environ. Sci. Tech., vol. 2, no. 1, pp. 13-26.

Act of 19 June 1997 banning the use of asbestos-containing products. Journal of Laws of 2004 No. 3, pos. 20, as amended.

Aspinall, RJ 1995, 'Geographic information systems: their use for environmental management and nature conservation', Parks, no. 5, pp. 20-31.

Bouziania, M, Goïtab, K \& Heb, D 2010, 'Automatic change detection of buildings in urban environment from very high spatial resolution images using existing geodatabase and prior knowledge', ISPRS Journal of Photogrammetry and Remote Sensing, no. 65, pp. 143-153.

Council Directive 87/217/EEC of 19 March 1987 on the prevention and reduction of environmental pollution by asbestos.

Dunnigan, J 1993, 'Chrysotile asbestos revisited', British Journal of Industrial Medicine, no. 50, pp. 862-863.

European Parliament resolution of 14 March 2013 on asbestos related occupational health threats and prospects for abolishing all existing asbestos (2012/2065(INI).

General Geographic Database of Poland, Ordinance of the Minister of Interior and Administration of 17 November 2011.

Goodchild, MF, Yuan, M \& Cova, TJ 2007, 'Towards a general theory of geographic representation in GIS', International Journal of Geographical Information Science, vol. 21, no. 3, pp. 239-260.

Goodchild, MF \& Haining, A 2004, 'GIS and spatial data analysis: Converging perspectives', Papers Reg. Sci., vol. 83, pp. 363-385.

Goodchild, MF 2000, 'The current status of GIS and spatial analysis', Journal of Geographical Systems, no. 2, pp. 5-10.

Longley, PA, Goodchild, M \& and Rhind, D 2005, Geographic Information Systems and Science, John Wiley \& Sons, Inc., New York.

National Register of Boundaries, Ordinance of the Council Ministers of 10 January 2012 on national register of boundaries.

Ordinance of the Minister of Economy of 13 December 2010 on requirements for the use of products containing asbestos and the use and cleaning of plant or equipment, which have been or are being used asbestos-containing products.

O'Sullivan, D \& Unwin, DJ 2010, Geographic Information Analysis, John Wiley \& Sons, Inc., New York.

Overman, HG 2010, 'GIS a job: What use Geographical Information Systems in spatial economics?', Journal of Regional Science, vol. 50, no. 1, pp. 165-180.

Programme for Asbestos Abatement in Poland 2009-2032, 2010. Resolution No. 39/2010 of the Council of Ministers.

Putra, S, Wenjing, L \& Yang, P 2003, 'Object-oriented GIS Data Modelling for Urban Design', proceedings from Map Asia Conference 2003. Available from: <http://www. gisdevelopment.net/application/urban/overview/pdf/ ma03093.pdf>. [10 December 2013].

Rob, MA 2003, 'Some challenges of integrating spatial and nonspatial datasets using a geographical information system', Information Technology for Development, vol. 10, pp. 171178.

Ross, MA, Langer, M, Nord, GL, Nolan, RP, Lee, RJ, Van Orden, D \& Addison, J 2007, 'The mineral nature of asbestos', Regulatory Toxicology And Pharmacology: RTP [Regul Toxicol Pharmacol], no. 52 (1 Suppl), pp. 26-30.

Salem, BB 2003, 'Application of GIS to biodiversity monitoring', Egypt Journal of Arid Environments, no. 54, pp. 91-114.

Salman Mahini, A \& Gholamalifard, M 2006, 'Siting MSW landfills with a weighted linear combination methodology in a GIS environment', Int. J. Environ. Sci. Tech., vol. 3, no. 4, pp. 435-445.

Skryzhevska, L, Green J \& Abbitt, R 2013, 'GIS Textbook Content as a Basis for Skill Development in Map Interpretation, Cartographica, vol. 48, no. 1, pp. 38-46.

de Smith, M, Goodchild, MF \& Longley, PA 2011, 'Geospatial Analysis - 4th Edition'. Available from: <http://www. spatialanalysisonline.com/HTML>. [2 December 2013].

Thompson, S \& Mason, E 2002, 'Asbestos: Mineral and fibers', Chemical Health And Safety, no. 9, pp. 21-23.

World Health Organization 2006, Elimination of asbestos-related diseases WHO/SDE/OEH/06.03. Available from: <http:// whqlibdoc.who.int/hq/2006/WHO_SDE_OEH_06.03_eng. pdf?ua=1>. [10 December 2013].

Virta, RL 2002, 'Asbestos: Geology, Mineralogy, Mining, and Uses 2002'. USGS Open-File Report: 2002-149. Available from: <http://pubs.usgs.gov/of/2002/of02-149/>. [10 December 2013].

Virta, RL 2003, 'Asbestos: Geology, Mineralogy, Mining, and 
MISCELLANEA GEOGRAPHICA - REGIONAL STUDIES ON DEVELOPMENT

Vol. $18 \cdot$ No. $2 \cdot 2014 \cdot$ pp. 59-64 • ISSN: 2084-6118 • DOI: 10.2478/mgrsd-2014-0019

Uses.', U.S. Department of the Interior, U.S. Geological Survey, Open-File Report 02-149. Available from: <http:// minerals.usgs.gov/minerals/pubs/commodity/asbestos/>. [10 December 2013].

Zerrouqi, Z, Sbaa, M, Oujidi, M, Elkharmouz, M, Bengamra, S \& Zerrouqi, A 2008, 'Assessment of cement's dust impact on the soil using principal component analysis and GIS', Int. J. Environ. Sci. Tech., vol. 5, no. 1, pp. 125-134. 